\title{
O ARQUIVO COMO UM "LUGAR PARA A HISTÓRIA" REFLEXÕES A PARTIR DA PRÁTICA DE PESQUISA EM HISTÓRIA DA EDUCAÇÃO NO OITOCENTOS $^{1}$
}

\author{
Juarez José Tuchinski dos Anjos ${ }^{2}$ \\ Universidade Federal do Paraná - UFPR
}

\section{RESUMO}

O objetivo do presente artigo é realizar a reflexão acerca de uma experiência de pesquisa em história da Educação sobre o século XIX, no Arquivo Público Municipal Casa da Memória da Lapa (PR), divulgando parte de seu acervo e ponderando sobre os desafios mais gerais da produção do conhecimento histórico, que passa pelo necessário confronto do historiador com os arquivos. Inicialmente, são tecidas breves considerações sobre o Arquivo "lugar de memória" e a transformação que a prática historiográfica nele realiza ao torná-lo, um "Lugar para a História". Na segunda parte, são apresentadas três dimensões de análise adotadas no questionamento da documentação do Arquivo Público Municipal Casa da Memória da Lapa, exemplificando-as com interpretações acerca de algumas experiências históricas da escola primária na Província do Paraná.

Palavras-Chave: Arquivo; História da Educação; Paraná; Século XIX ; Lapa.

\section{THE ARCHIVE AS A "PLACE FOR HISTORY" REFLECTIONS ON THE PRACTICE OF RESEARCH IN HISTORY OF EDUCATION IN THE $19^{\text {th }}$ CENTURY .}

\begin{abstract}
The present article aims to reflect on a research experience in History of Education in the $19^{\text {th }}$ century in the Municipal Public Archive Casa da Memória da Lapa (State of PR), disclosing part of its collection and pondering the most general challenges of the production of historical knowledge, which goes through the necessary approach of the archives by the historian. Initially, brief considerations are made on the Archive "place of memory" and its transformation performed by the historiographical practice by turning it into a "Place for History". The second part presents three dimensions of analysis adopted in the questioning of the documentation of the Municipal Public Archive Casa da Memória da Lapa, exemplified with interpretations of some historical experiences in the elementary school in the Province of Paraná.

Keywords: Archive; History of Education; Paraná; $19^{\text {th }}$ century; Lapa.
\end{abstract}


O Arquivo Público Municipal "Casa da Memória” (APMCM), situado na cidade da Lapa, a $70 \mathrm{~km}$ de Curitiba, possui um dos maiores acervos disponíveis para pesquisa no Estado do Paraná. Seu corpus documental pode ser balizado de meados do século XVIII até fins do século XX, numa ampla variedade de documentação: processos criminais, processos cíveis, inquéritos policiais, inventários, atas da Câmara Municipal, livros da Guarda Nacional, Correspondências da Guarda Nacional, Livros de Eleitores, ofícios da administração municipal, fotografias do século XIX e princípios do século XX, livros copiadores de correspondências entre tropeiros e autoridades municipais, recortes de jornais locais do século XIX, relatórios oficiais da Província e do Império, livros que integravam a Biblioteca da Associação Literária Lapeana (associação Oitocentista), Livros de Comércio (venda, débitos e haveres), registros de matrículas de escravos, listas nominativas de habitantes e, naquilo que mais interessa ao historiador da educação, fontes referentes à instrução pública, mais especificamente, no Oitocentos.

A documentação acima descrita e custodiada neste arquivo denominado "Casa da Memória" reflete bem aquilo que ele quer representar: uma memória sobre a história da própria cidade. Surgida como pouso das tropas que vinham de Viamão, no Rio Grande do Sul, rumo à Sorocaba, em São Paulo, para a grande feira de animais que lá se realizava anualmente, a povoação fundada por renóis tornou-se Freguesia em 1769, vila em 1806 e cidade em 1872. No ano de 1894, viveu a experiência de 26 dias de sítio, durante a Revolução Federalista, num episódio que ficou conhecido como "O Cerco da Lapa". Ao longo do século passado, a cidade foi gradativamente tombada pelo Instituto do Patrimônio Histórico e Artístico Nacional sendo que a própria criação do Arquivo Público Municipal se deu no bojo desse processo de preservação da história e produção de memória, no ano de 1992.

No campo educacional, a Lapa contou com escolas públicas desde 1832 e 1848, para meninos e meninas, respectivamente (KUBO, 1986, p. 314-315), além de várias escolas particulares, assim como cadeiras isoladas de ensino secundário de francês e latim. $\mathrm{Na}$ década de 1870 foi lugar de tentativa de criação de uma escola noturna para adultos, que interrompida, foi retomada em 1882. Em função de ao longo do período provincial ter funcionado ali uma das sedes de inspetoria de instrução (PARANÁ, 1854), parte da documentação trocada com agentes da instrução em cidades vizinhas como Curitiba, Palmeira, Rio Negro e São João do Triunfo também podem ser encontradas na Casa da Memória, oferecendo assim a possibilidade de investigações não apenas sobre a história da escola na Lapa, mas também da sua organização na própria Província do Paraná.

O objetivo do presente artigo é realizar uma reflexão sobre minha prática de pesquisa no Arquivo Público da Lapa, divulgando parte de seu acervo e ponderando sobre os desafios mais gerais da produção do conhecimento histórico, que passa pelo necessário confronto do historiador com os arquivos. Inicialmente, teço breves considerações sobre o Arquivo "lugar de memória" e a transformação que a prática historiográfica nele realiza ao torná-lo, tomando de empréstimo o título do livro de Arlette Farge (1999), um "Lugar para a História". Em seguida, passo à apresentação de três dimensões de análise adotadas no questionamento da documentação da Casa da Memória da Lapa, exemplificando-as com interpretações acerca de algumas experiências históricas da escola primária na Província do Paraná.

\section{O arquivo: de "lugar de memória" a "lugar para a história"}

$\mathrm{O}$ arquivo constitui-se em instrumento de custódia e preservação de determinada documentação considerada importante para aqueles que o instituem - uma instância de 
governo, por exemplo - ou que o organizam - seus arquivistas. Estes partem de uma lógica, cujas linhas gerais são mais ou menos as apontadas por Clarice Nunes e Marta Carvalho, onde a concepção corrente "é a valorização enfática dos documentos enquanto objetos de caráter comprobatório (...). O valor informativo, que se refere ao uso do documento do ponto de vista científico, raramente é considerado" (NUNES; CARVALHO, 2005, p. 33). Essa lógica do arquivo impõe, já de início, consideráveis limitações à produção do conhecimento histórico que o toma por base, na medida em que descarta com frequiência boa parte da documentação que poderia apresentar as contradições presentes nos processos históricos, as lutas e tensões entre o Estado ou uma instituição e os sujeitos que os integram, por exemplo.

A vontade de preservar apenas o que se considera importante sobre a trajetória de um grupo, de uma cidade ou de uma instituição, torna o Arquivo, aproximando-me das considerações de Pierre Nora e Peter Burke, um lugar de memória, no sentido lato do termo: um lugar material, simbólico e funcional (NORA, 1993, p. 21) onde nenhuma memória é espontânea, mas criada (Idem, ibidem, p. 13), a serviço tanto uma memória social como também de uma amnésia social (BURKE, 1992).

No primeiro caso, o da memória social, o Arquivo torna-se o lugar que ajuda a apresentar às gerações futuras determinadas imagens do grupo ou instituição que nele deposita sua documentação, das quais se constitui baluarte e guardião. Ele oferece, a partir de um conjunto de realidades que ajuda a recordar, uma identidade para o grupo que o institui. No segundo caso, o da amnésia social, ele constitui-se no lugar que sentencia ao esquecimento aquilo que seus mantenedores ou organizadores consideraram não importante ou mesmo indesejado de ser lembrado nessa memória social em construção. $\mathrm{O}$ arquivo "lugar de memória" serve, então, tanto para recordar o passado como para esquecer e "apagar" algumas das suas facetas.

Entretanto, mesmo o Arquivo estando delimitado, "enquadrado" a uma imagem mais ou menos selecionada pelos grupos e atores que tem o poder de arquivar, é possível, a partir dele, elaborar outras explicações, diferentes dessa memória que produz e testemunha, porque, como recorda Arlette Farge

O arquivo é uma brecha no tecido dos dias, a visão retraída de um fato inesperado. Nele, tudo se focaliza em alguns instantes de vida de personagens comuns, raramente visitados pela história, a não ser que um dia decidam se unir em massa e construir aquilo que mais tarde se chamará história. $O$ arquivo não escreve páginas de história. (FARGE, 2009, p. 14, grifo meu)

Portanto, por maior que seja a força da lógica do arquivo - a lógica da memória ele não é nem nunca será história, mas somente mais um dos elementos que integram os fenômenos históricos, prenhe de historicidade sem dúvida, mas que como todos os objetos históricos, só fala quando interrogado. Com efeito, o Arquivo passa a "falar de outro jeito" quando tomado como a base para a produção do conhecimento histórico, que também não pretende ser a História "real" (cf. THOMPSON, 2009, p. 31), mas, antes, a compreensão de evidências, "certamente dotadas de existência real, mas que só se tornam cognoscíveis segundo maneiras que são e devem ser a preocupação dos vigilantes métodos históricos" (Idem, ibidem, p. 57). Esses métodos dizem respeito a um conjunto de procedimentos integrantes da "lógica do historiador", um 
...método lógico de investigação adequado à materiais históricos, destinado, na medida do possível, a testar hipóteses quanto à estrutura, causação, etc. e a eliminar procedimentos autoconfirmadores ("instâncias", "ilustrações"). O discurso histórico disciplinado da prova consiste num diálogo entre o conceito e a evidência, um diálogo conduzido por hipóteses sucessivas, de um lado, e a pesquisa empírica, do outro. O interrogador é a lógica histórica; o conteúdo da interrogação é uma hipótese (...) o interrogado é a evidência, com suas propriedades determinadas. (Idem, ibidem, p. 57).

A passagem de uma lógica à outra não é de modo algum simples ou fácil. Exige que o historiador desenvolva a habilidade de articular o que desaparece sobre aquilo que aparece (FARGE, 1999, p. 7), fazendo com que o arquivo não se limite a ser um lugar de memória, mas torne-se também, parafraseando o título do livro de Arlette Farge (1999), um Lugar para a escrita da História. Ainda nesse processo de diálogo e questionamento dos documentos que repousam no Arquivo, avisa-nos Clarice Nunes, o historiador há que ultrapassar também, por meio de sua prática de pesquisa

...as fronteiras entre corpos teóricos produzidos por diferentes disciplinas, com objetivos e histórias diferentes; que o levam a construir e reconstruir categorias, não só para apreender os objetos de ângulos imprevistos, mas principalmente para ultrapassar a sua descrição e permitir um tratamento crítico. (NUNES, 2005, p. 39)

É quando se opera essa passagem do Arquivo "Lugar de Memória" para o Arquivo "Lugar para a História", que os documentos que o integram tornam-se fontes para a pesquisa histórica, ou testemunhas, como Marc Bloch preferia designá-los. Ainda que tais testemunhas possam ser imagens ou objetos, especialmente sobre a Instrução Pública no século XIX e no APMCM, o que mais encontrei durante o tempo em que lá pesquisei foram fontes escritas: ofícios, relatórios, mapas escolares. Experiências históricas inscritas em textos. Não quero com essa consideração minimizar a compreensão de fonte histórica que temos em nosso ofício, pois concordo plenamente com Marc Bloch que "tudo o que o homem diz ou escreve, tudo o que fabrica, tudo o que toca pode e deve informar sobre ele" (BLOCH, 2001, p. 79). Porém, ao encaminhar minha reflexão para este tipo de fonte pensando-a em sua relação com o Arquivo, proponho elencar o que "aparece" nos testemunhos escritos para compreender o que está "desaparecido" neles e pode vir à tona por meio dos questionamentos do historiador, alargando os domínios da memória, no singular, para, a partir deles, escrever histórias, no plural.

No enfrentamento deste corpus documental, procurei articular três dimensões de análise que me pareceram oportunas para o trato daquelas fontes escritas: as justificativas presentes nos textos, as tensões que eles ocultam e a potencialidade do testemunho do texto escrito como acontecimento histórico. Para pensar cada uma dessas dimensões de análise, busquei dialogar com a teoria sem descuidar da sua exeqüibilidade prática, ou seja, procurei pensar a teoria enquanto uma maneira de interrogar as evidências históricas às quais as fontes escritas davam acesso, em consonância com a lógica histórica. Estas três dimensões analíticas são apresentadas a seguir, discutidas e exemplificadas com algumas interpretações sobre as experiências históricas da escola primária na Província do Paraná, construídas no confronto diário de um historiador com os seus arquivos.

\section{2. $O$ arquivo e seus textos: Lugares para a escrita da história}




\subsection{As justificativas presentes nos textos}

Com alguma freqüência, depois de certa intimidade com a documentação que vinha lendo e relendo na Casa da Memória da Lapa, observei que muitas vezes os textos arquivados cumprem o objetivo de justificar. Isso se torna bastante sensível nos textos produzidos por pessoas que ocupam diferentes lugares dentro de determinado grupo social. Quase sempre - senão sempre! - a justificativa parte do "subordinado" ao "superior", testemunhando determinadas coações postas em movimento nos processos históricos, que não são naturais, mas socialmente construídas. $\mathrm{O}$ ato de justificar aponta as relações de interdependência mantidas entre os sujeitos ao longo do tempo, dentro de determinadas figurações sociais. O conceito de figuração conforme desenvolvido por Norbert Elias (2001) vai nos remeter a um tipo de organização social no qual seus membros estão interligados por relações de dependência, exercidas, sobretudo, a partir de funções que desempenham uns para com os outros. Quando lidas as justificativas dos textos a partir dessa noção de figuração social, podem emergir situações inesperadas nas quais o sujeito que justifica pode revelar ao sujeito ao qual justifica a existência de um terceiro membro da figuração, aquele sobre o qual se justifica e que em determinados momentos assume um poder - entendido como a extensão especial "da margem individual de ação associada a certas posições sociais, expressão designativa de uma oportunidade social particularmente ampla de influenciar a auto regulação e o destino de outras pessoas" (ELIAS, 2009, p. 50) - maior até que aquele do que se encontra no topo da hierarquia de determinada figuração.

Um exemplo de como isso ocorria vem de um ofício enviado pelo Inspetor Geral da Instrução Pública do Paraná ao Inspetor Paroquial da Lapa em 1872, sobre as explicações dadas pelo professor da $1^{a}$ Cadeira do Sexo Masculino da Lapa, Geniplo Pereira Ramos, acerca de não poder apresentar alunos à exame naquele ano:

Ilmo. Sr.

Fiquei ciente de haver declarado a V. S. o professor da $1^{\text {a }}$ Cadeira do sexo masculino desta cidade, Geniplo Pereira Ramos, que não pode este ano apresentar alunos a exames, pois deseja aprontá-los mais no ano vindouro bem versados nas matérias que fossem objeto do ensino, principalmente quando um deles tem faltado muito à escola. Não há remédio senão conformar-me com a razão apresentada por este professor. Contudo, queira V. S. fazer-lhe ver que não é estranho quando semelhante notícia vem de um professor novo e ainda sem tirocínio, mas que partindo ela de um professor experiente, não podia deixar de causar-me cruel decepção. (APMCM, Ofício Inspetor Geral, 16/11/1872).

No caso em questão, encontramos o Inspetor Geral da Província nem um pouco satisfeito com a situação que impedia o professor da $1^{a}$ Cadeira de apresentar alunos à exames, "cruelmente decepcionado", podemos definir a partir de suas próprias palavras. Todavia, confessava não ter outro remédio, senão conformar-se à situação. Essa conformidade expressa a compreensão que ele, mesmo a contragosto, tinha juntamente com o professor de que para algumas coisas - como o caso da realização dos exames - de fato, dependia-se inteiramente dos alunos. Dependia-se de suas habilidades intelectuais, que em menos tempo poderiam deixá-los "versados nas matérias que fossem objeto do ensino", mas, também, que aqueles melhor preparados não faltassem às aulas, garantindo 
ao professor que o menino apresentado à exames fosse, além disso, aprovado. Ora, tanto o sujeito que justifica como o que recebe a justificativa nada mais puderam fazer senão contentar-se ante a realidade de que o aluno - quase sempre a criança - naquele momento, dentro daquela oportunidade social do exame, na figuração social da escola, exercia um poder maior do que aquele habitualmente concedido a ele e em decorrência disso, impossibilitava a realização dessas provas, cujos resultados eram ansiosamente aguardados para serem divulgados e propalados pelos presidentes da Província em seus relatórios, como "termômetro" do bom funcionamento da escola e da capacidade do governo em fazêla funcionar.

Uma outra situação semelhante aponta novamente essas relações de interdependência estabelecidas entre os professores, seus alunos e as famílias destes, para que se chegasse à tão desejada meta da conclusão da escolarização. Chama nossa atenção, porém, para o fato de que a criança - é novamente ela o "sujeito sobre o qual se justifica" também exercia esse seu poder de interferência por meio da mediação do adulto, que ao retirá-la da escola, privava o mestre do aluno, sem a qual, não havia possibilidade de exame. Quem escreve é a professora Rita Idalina de Carvalho. Em seu relatório anual, a professora segue discorrendo sobre o estado da instrução em sua escola e o valor que esta teria para as meninas, publico de sua cadeira. Em determinada altura, quando chega a hora de argumentar e justificar, ponderou que:

\begin{abstract}
Mal, porém, se tem compreendido entre nós essa necessidade [a instrução das mulheres], pois em geral os nossos chefes de família contentam-se apenas que suas filhas assinem o seu nome, leiam alguma coisa, e façam as quatro operações aritméticas, conhecimentos estes que em breve ficam esquecidos, porque as meninas, permanecendo pouco tempo na escola, não compenetram verdadeiramente do que aí aprenderam. (...) Esse fato, que não é peculiar deste lugar, dá-se na escola que rejo e daí o pequeno número de alunas habilitadas para exame anual. (APMCM, Ofício professora Rita Idalina de Carvalho 20/11/1877)
\end{abstract}

As justificativas apresentadas pela professora pública retomam as relações de interdependência na figuração da escola que já conhecemos - sem alunos preparados, não havia como realizar os exames finais - mas aponta também o quanto o valor atribuído à instrução pelas famílias exercia sua parcela de influência e pesava na decisão dos pais de permitir que as filhas continuassem ou não a instrução. De acordo com a professora, estes pais retiravam as alunas da escola quando percebiam que as meninas já sabiam assinar o nome, ler alguma coisa e fazer as quatro operações. Embora a mestra, no intento de justificar, classifique esses saberes como apenas um pouco do que se pode aprender (e de fato, eram pouco para se chegar a exames finais) para os chefes de família eles eram suficientes. Se com esses saberes, que na opinião da professora eram rapidamente esquecidos, não se fazia exames finais, o que é que as meninas, na ótica dos pais, poderiam fazer? A resposta, neste caso especifico, terá de ser deduzida, a partir de alguns indícios presentes neste mesmo ofício e em outros documentos do Arquivo Público da Lapa, operação legítima no ofício do historiador, na qual onde é impossível calcular, impõe-se por vezes sugerir (BLOCH, 2001, p. 55).

Sabendo assinar o nome, as meninas já teriam condições de delegar aos maridos procurações para resolverem questões relativas à terrenos e negócios, o que se evidencia num rápido olhar sobre documentação judicial custodiada no Arquivo da Lapa, onde é elevado o número de procurações concedidas pelas mulheres à seus maridos, para resolverem questões quase sempre ligadas à ampliação do patrimônio do casal. Ler 
"alguma coisa", por outro lado, já serviria para terem um mínimo contato com a cultura escrita, através da qual poderiam informar seus pais e esposos (se esses eventualmente não soubessem ler) sobre assuntos pontuais, como editais da câmara habitualmente afixados na porta da matriz ou sobre alguma nova postura municipal colocada em circulação na cidade. Por fim, por meio das quatro operações aritméticas, poderiam colaborar com os pais e maridos na elaboração e controle das contas da casa, a tão propalada economia doméstica, que mais do que saber costurar e bordar, exigia a capacidade de calcular o quanto de cada coisa era necessária para o provimento da cozinha de uma casa, por exemplo. A própria mestra Rita Idalina, em outra parte do seu ofício, informa que era para empregarem-se nos trabalhos domésticos que os pais retiravam as filhas da escola (APMCM, Ofício Rita Idalina de Carvalho, 20/11/1877). Tais trabalhos poderiam, muito bem, se referir ao tipo de atividades aventadas acima.

Deixando o terreno das suposições para voltarmos aquele um pouco mais firme, o das justificativas, emerge através de ambos os textos analisados testemunhos claros da influência de sujeitos hierarquicamente "inferiores" dentro da figuração social da escola: crianças que não freqüentam as aulas, meninos que não aprendem, meninas que são retiradas da escola, pais que intentam para as filhas usos distintos dos saberes que a escola quer transmitir. Diante disso, podemos afirmar que mesmo quando os textos dos arquivos, na sua força de memória, apenas expressam relações de interdependência conhecidas - do professor com o inspetor paroquial, do inspetor paroquial com o inspetor geral - uma série de outras relações também estão contidas neles, nas suas entrelinhas, sendo acessíveis aos questionamentos que busquem identificá-las.

\subsection{Nos textos arquivados, tensões entre as autoridades provinciais}

Uma segunda dimensão para análise dos textos do arquivo é de que mesmo sendo mantidos dentro de uma lógica da memória, que é movida sempre por um desejo de coerência e "harmonia", não conseguem esconder as tensões entre as próprias autoridades provinciais. Para a identificação desse tipo de tensão, porém, é preciso ampliar o olhar sobre a escola e a documentação a ela referente. Dario Ragazzini já classificava em dois grupos as fontes para a história da educação: as fontes da escola, que provém das práticas escolares e as fontes para a história da escola, que "auxiliam a interpretar e a escrever essa história." (RAGAZZINI, 2001, p. 19). Posto isso, uma dessas fontes para a história da escola e das quais me servi ao longo da pesquisa foram os documentos da Câmara Municipal da Lapa, nos quais, a partir do cruzamento com outras fontes de igual natureza, pude identificar tensões entre as autoridades municipais e provinciais no tocante à organização da escola pública primária.

Penso que quando se fala em "tensão", deve-se ponderar que nem sempre ela é declarada e na maioria das vezes só emerge por meio de certos questionamentos a que as evidências históricas são submetidas. Acima de tudo, ela só aparecerá se, de fato, estiver contida - mesmo que escondida - na evidência, pois como lembra Edward Thompson

A evidência histórica tem determinadas propriedades. Embora lhes possam ser formuladas quaisquer perguntas, apenas algumas serão adequadas. Embora qualquer teoria do processo histórico possa ser proposta, são falsas todas as teorias que não estejam em conformidade com as determinações da evidência. É isto que constitui o tribunal de recursos disciplinar. (THOMPSON, 2009, p. 58). 
Uma evidência de tensão presente especialmente nos discursos dos presidentes da Província era de que as municipalidades, conforme designadas no período as câmaras municipais, não abraçavam a causa da instrução, fazendo com que a responsabilidade sobre a organização da escola pesasse toda sobre os ombros da Província. Entretanto, na documentação da Câmara da Lapa, durante todo o período pesquisado, encontrei a instrução pública comparecendo de diferentes maneiras entre as preocupações dos edis. Em relatório apresentado à Província, em 16 de Janeiro de 1855, por exemplo, assim a Câmara se manifestava sobre a instrução pública:

\begin{abstract}
A instrução primária, base principal da civilização e que tão eficazmente concorre para a felicidade pública, é aqui ministrada com lentidão e tendo-se tirado às câmaras a inspeção que se exercia sobre as aulas, não lhe é lícito hoje indagar das causas e nem propor os meios de resolvêlas. Entretanto não pode a câmara prescindir do dever de invocar a atenção de V. Sa. sobre esse importantíssimo objeto, sendo como é certo, que a população cresce e com ela o desejo e a necessidade de instrução, pois que existindo aqui duas aulas públicas e uma particular, são elas freqüentadas por 99 alunos de ambos os sexos a saber: aula do sexo masculino 59, na do sexo feminino 31, na aula onde contra a lei provincial paulistana se admitem alunos de ambos os sexos, 6 meninos e 6 meninas. Na aula da freguesia do Rio Negro, onde os progressos do ensino não são satisfatórios, aprendem 19 meninos. Acaba de abrir nesta vila uma nova aula para onde se ensinam a gramática nacional, a francesa, a geografia, geometria e história, que foi instalada com seis alunos. Manifestando a Câmara o desejo de ver prosperar a instrução primária, está bem longe de supor falta de habilitações naqueles a quem ela está aqui confiada. (APMCM, $3^{\circ}$ Livro Copiador da Câmara, p. 98v, grifos meus).
\end{abstract}

Os vereadores neste relatório emitem opinião tanto sobre a situação da instrução na então Vila do Príncipe e na sua freguesia do Rio Negro como sobre o lugar que lhes estava sendo conferido pela legislação em relação à instrução. No tocante ao primeiro aspecto, os vereadores declaram que a instrução era ministrada com lentidão, havia escolas inclusive que, contrariando a lei paulista (o Regulamento de 1846, que ainda regia a instrução na Província e que vigorou no Paraná até 1857) recebiam alunos de ambos os sexos; na freguesia do Rio Negro os progressos não eram satisfatórios e que apesar disso tudo (!) a Câmara estava bem "longe de supor a falta de habilitações naqueles a quem ela está aqui confiada".

Em relação ao segundo aspecto - não estarem autorizados a inspecionar as aulas os vereadores da Vila do Príncipe, indiretamente, manifestam descontentamento ao que estava sendo proposto pelo Presidente da Província Zacarias Goes de Vasconcellos, que em relatório apresentado um ano antes, se mostrava disposto a manter o que vinha prescrito no Regulamento Paulista, minimizando o poder de ação das Câmaras sob a inspeção das escolas, inclusive determinando que nos exames finais a que os alunos deviam ser submetidos como forma de conclusão da escolarização, a comissão examinadora fosse designada pelo Presidente e não pelas Câmaras. Na opinião do Presidente Zacarias, nessa prática da comissão examinadora ser nomeada pelos vereadores, "sobressai o desacerto de aquinhoar melhor as municipalidades que o governo da província na justa intervenção que lhe cumpre exercer sobre as escolas" (VASCONCELOS, 1854, p. 14). Ao tecerem críticas à situação da instrução e evocarem o cerceamento de sua autoridade sobre as escolas, os vereadores talvez tentassem sugerir que se a situação fosse 
outra - na qual tivesse o necessário poder de inspeção e vigilância - o quadro descrito (e que inclusive não lhes caberia relatar, já que não dizia respeito à sua alçada), poderia ser outro.

Estamos agora em 1873. Novamente, a Câmara da Lapa apresenta seu relatório sobre o estado geral do município e, como nos anos anteriores ${ }^{3}$, inclui considerações sobre a Instrução Pública:

\begin{abstract}
Atualmente, há três escolas públicas, uma do sexo feminino e duas do sexo masculino. Ultimamente nota-se grande diminuição na sua frequiência, mas este fato devemos atribuir ao expediente que tomaram alguns chefes de família na cidade e fora dela de contratarem professores particulares. Pelo recenseamento feito ultimamente, verifica-se que o município ainda conta maior número de pessoas analfabetas do que as que sabem ler e escrever, esse fato devido, sem dúvida, a se achar a população muito espalhada, é digno de lástima. (APMCM, Parecer da Câmara relativo ao ano de 1873).
\end{abstract}

De novo encontramos os vereadores fazendo considerações não pouco significativas sobre a instrução pública na cidade. Na primeira delas, diagnosticam um problema - a diminuição da frequiência nas escolas - mas apressam-se em apontar a causa: não poderia ser ela devida ao descaso dos pais de família com a instrução dos filhos, mas à sua iniciativa de contratar professores particulares. Por outro lado, ao não explicarem a razão pelas quais os pais faziam isso, deixavam uma série de reticências a serem preenchidas pelas reflexões do presidente da Província, a quem dirigiam seu relatório. A segunda consideração novamente trabalha com o duo "situação-causa". Lamentando que o número de analfabetos segundo o censo de 1872 fosse muito maior que o de pessoas que sabiam ler e escrever, não atribuíam a causa à improbidade dos pais em enviar os filhos à escola, mas antes ao fato da população viver muito disseminada. ${ }^{4}$ Ou seja, os vereadores, em ambos os casos, discorrem sobre a instrução e tecem suas considerações, sugerindo que estão bastante vigilantes sobre ela. Não estavam, assim, nem um pouco omissos ou alheios a esse importante ramo do serviço público.

Mas, se "intromissões" da Câmara como essas ocorriam, demonstrando seu interesse pela Instrução, qual a razão dos presidentes afirmarem que as municipalidades não se envolviam com a Instrução Popular, quando opiniões como a dos vereadores da Lapa em 1855 e 1873 foram uma constante ao longo do período Provincial? Creio que o presidente Lamenha Lins nos dá uma pista quanto à isso, no seu relatório do ano de 1876:

A municipalidade é criadora e mantenedora natural da escola. Sobre ela é que deve pesar este grande encargo, que demanda o esforço combinado de todas as vontades. Nos Estados Unidos, a comuna (...) desempenha por si só todas as obrigações inerentes ao ensino público, o Estado exerce apenas o seu direito de fiscalização, vindo algumas vezes em auxílio delas. (LAMENHA LINS, 1876, p. 49, grifos meus).

Diante da fala deste presidente, da queixa dos vereadores da Lapa que conhecemos em 1855 e das sutis observações de 1873, fica bastante claro que a tensão girava em torno do papel de vigilância a ser desempenhado: seria este responsabilidade da Câmara (como queriam os vereadores) ou da Província (como queria o presidente Lamenha Lins)? No entanto, mais do que uma disputa para ver "quem é que manda" na escola, estava a da consequiente desobrigação de outra dimensão inerente à instrução pública: a manutenção financeira da escola. Para o Presidente, inspirado na experiência norte-americana, essa 
devia ser a responsabilidade das municipalidades. Essas, pelo contrário, queriam agir na inspeção, mas não na manutenção das escolas públicas. No caso das câmaras, isso pode se dever não tanto a uma má vontade, mas a própria escassez de recursos de que dispunham. No caso da Província, sem dúvida, a falta de verbas era a razão principal de ser angustiadamente desejado o envolvimento das municipalidades, diminuindo a ônus da instrução nos cofres públicos.

Duas evidências, de certo modo ligadas, autorizam essa interpretação. A primeira delas diz respeito à ausência completa de despesas por parte da Câmara da Lapa com a instrução pública até o ano de 1882. A partir de então, encontram-se nos seus balanços duas ordens de despesas: pagamentos feitos ao professor da escola noturna municipal, mantida pela Câmara e gastos com a construção de uma casa escolar na cidade (APMCM, Balanços da Câmara, 1882-1889). O pagamento do professor passou a ser feito a partir da determinação do presidente da Província de que fossem criadas nas cidades escolas noturnas para adultos trabalhadores, a fim de que estes se preparassem para participar do processo eleitoral, que em função da reforma de 1882, exigia que o eleitor soubesse ler e escrever (CARVALHO, 1882, p. 92). A outra despesa ficou imposta pela lei $\mathrm{n}^{\circ} 734$, de 22 de outubro de 1883, que determinava a construção de casas escolares por parte das Câmaras Municipais (PARANÁ, Lei n. 734, 1883) e que com maior ou menor agilidade, foi sendo posta em prática no Paraná e o foi também na cidade da Lapa. A segunda evidência é que, a partir de então, embora ainda possam ser encontradas criticas as municipalidades, elas passaram a merecer de vez em quando, elogios por estarem somando esforços com a Província para o desenvolvimento da instrução pública... Que este envolvimento não foi espontâneo, as leis e ordens acima evocadas o testemunham. Mas, que ele surtiu efeito, os gastos efetuados pela Câmara da Lapa o confirmam. E que o envolvimento das municipalidades - o envolvimento desejado pela administração provincial e não aquele desejado pelos vereadores - ocorreu, ainda que por meio de algumas tensões e imposições, o conjunto das evidências possibilita apreender.

\subsection{Nos textos escritos, estão inscritos acontecimentos}

A última dimensão de análise sobre a qual gostaria de chamar a atenção é de que os textos dos arquivos são acontecimentos para o historiador. Embora o acontecimento tenha sido relegado por grandes historiadores como Marc Bloch, Lucien Febvre e Fernand Braudel - com justas razões naquele contexto, é preciso que se reconheça - recentemente ele tem sido retomado como um problema fecundo para a produção de interpretações históricas, conforme sintetizou Jacques Revel (2009). Todavia, o que é o acontecimento na pesquisa histórica? Não é o mesmo acontecimento político que refutaram os pais fundadores dos Annales. Acredito que Paul Veyne foi quem melhor definiu o acontecimento à luz do seu retorno na prática historiográfica. Acontecimentos - escreve Veyne - "não são coisas (...) eles são um corte que operamos livremente na realidade" (VEYNE, 1998, p. 46), ou seja, uma escolha deliberada do historiador, que decide colocar sua atenção naquilo que, à luz de certa ordem de questionamentos, pode fornecer pistas explicativas para os fenômenos históricos que quer compreender. Esse uso do acontecimento serve hoje em dia, salienta Jacques Revel

à reflexão sobre o entrelaçamento das durações históricas, sobre a experiência dos atores e pode propiciar a reflexão sobre a incerteza que caracteriza essa experiência e que os historiadores tendem (porque eles vêm depois) a ignorar. (REVEL, 2009, p. 87). 
Assim, podemos dizer que o acontecimento permite obter novas explicações para determinados fenômenos, sem torná-las absolutas, mas assumindo que se fazem a partir da perspectiva escolhida pelo historiador; e ao mesmo tempo perceber como as escolhas dos sujeitos neles envolvidos os produzem e os entrelaçam com a experiência da temporalidade maior com as quais mantém algum tipo de relação. O Arquivo Público da Lapa oferece, assim, inúmeros acontecimentos, desde que se deseje interrogá-los dessa forma.

Um acontecimento que aqui gostaria de indagar e compreender são as experiências históricas testemunhadas por dois ofícios enviados pelos professores Geniplo Pereira Ramos, da Lapa e Francisco Bueno Freire, de Rio Negro, em outubro de 1872, dando informações sobre suas carreiras docentes. $\mathrm{O}$ acontecimento para eles foi a necessidade de prestarem informações sobre sua carreira ao Inspetor Geral. O acontecimento para mim, advindo do testemunho involuntário, são as experiências de ser professor no Oitocentos, na relação desta categoria de sujeitos com a sociedade na qual estavam mergulhados, que eles permitem apreender. Não se trata de deturpar as experiências históricas, mas reconhecer com Thompson que embora os historiadores possam selecionar suas evidências

... e escrever uma história dos aspectos isolados do todo (...) o objeto real continua unitário. O passado humano não é um agregado de histórias separadas, mas uma soma unitária do comportamento humano, cada aspecto do qual se relaciona com outros de determinadas maneiras (...) Na medida em que essas ações e relações deram origem a modificações, que se tornam objeto de investigação racional, podemos definir essa soma como um processo histórico, isto é, práticas ordenadas e estruturadas de maneiras racionais. Embora essa definição surja em resposta à pergunta formulada, esta não inventa o processo. (...) O objetivo da disciplina história é a consecução dessa verdade da história. (THOMPSON, 2009, p. 59).

Segundo os ofícios desses professores, arquivados na Casa da Memória da Lapa, em 1865, com o consentimento das autoridades provinciais, realizaram uma permuta de cadeiras entre si. O primeiro deles era Francisco Bueno Freire. Nomeado professor na freguesia do Iguaçu em 1864 (atual município de Araucária), foi removido no mesmo ano para a Vila do Príncipe (Lapa) e em 1865, por meio de permuta com Geniplo Ramos, tornou-se professor na Vila de Rio Negro. (APMCM, Ofício Francisco Freire, 15/10/1872). Já Geniplo Pereira Ramos, ao que parece, mais velho na profissão, foi nomeado professor adjunto em 21 de dezembro de 1860 e no ano seguinte, nomeado vitalício, sempre na Vila de Rio Negro. De lá, só saiu em 1865, por ocasião da permuta com o professor Francisco Freire. (APMCM, Ofício Geniplo Pereira Ramos, 12/10/1872). E na Lapa Geniplo permaneceu até o fim de sua carreira. O mesmo, porém, não ocorreu com o professor Freire. Antes de entrarmos nisso, gostaria de acrescentar uma informação oferecida por estes dois professores, relativa às licenças que solicitaram entre 1865 e 1872 . O professor Geniplo afirmava só recordar-se de duas: 9 a 13 de junho de 1871 (cinco dias) e 28 de novembro a 7 de dezembro do mesmo ano (9 dias, portanto). Já o professor Francisco, tirara por duas vezes licenças de 2 meses cada, embora o ano exato delas esteja ilegível no ofício cujo testemunho estamos interrogando.

Pouco mais de dois meses após escrever o ofício onde buscamos parte das informações aqui mobilizadas, Francisco Freire saiu do anonimato para a história, ou melhor, para o Relatório do Inspetor Geral da Instrução Pública, João Franco de Oliveira Souza. Dava notícia o inspetor geral de que em 12 de dezembro fora instaurado processo 
contra o referido professor, por abandono da cadeira que regia, sem a devida licença dos superiores (SOUZA, 1872, p. 9). Por meio de um ofício dirigido pelo subinspetor da Vila de Rio Negro ao Inspetor da Lapa, com data de 27 de novembro de 1871, chega a nosso conhecimento que o abandono da escola teria ocorrido em 16 de novembro, sendo que a 22 do mesmo mês - e aqui damos a palavra ao Subinspetor de Rio Negro "veio-me às mãos um ofício do mesmo [o professor Francisco] no qual pedia que obtivesse sua demissão, por não se achar com a capacidade precisa para exercer o Magistério" (APMCM, Ofício Subinspetor da Vila do Rio Negro, 27/11/1872). No relatório, o Inspetor Geral, sem nenhuma cerimônia, expôs o que, na sua ótica, teria sido a verdadeira causa do abandono da cadeira da parte do professor público:

Havia chegado ao meu conhecimento que este professor portava-se mal, embriagava-se com frequiência e tinha colocado a escola em tal grau de descrédito que apenas era freqüentada por poucos alunos. Entre esses, sequer podia manter ele o respeito e no meio dos seus concidadãos gozava da pior reputação. Sabedor desse procedimento tão censurável, pareceu-me que era indispensável submeter aquele funcionário e a escola por ele regida a uma severa sindicância e encarregando dessa tarefa o doutor Francisco Alves Guimarães, digno inspetor daquele distrito, houve-se ele com louvável moderação, resultando de suas pesquisas a confirmação destes fatos tão indignos de um mestre." (SOUZA, 1872, p. 9, grifos meus).

Diante da situação, o professor ao ver-se em vias de ser processado, nas palavras do Inspetor Geral "não esperou mais (...) abandonou a cadeira e lá seguiu caminho de Campos Novos, segundo ele próprio comunicou-me. Feliz retirada. Assim todos os maus professores lhe imitassem" (Idem, ibidem). E essa é a última informação obtida sobre o professor Francisco Bueno Freire.

Bem, mas, qual a importância desse acontecimento, ou, como diria Braudel, essa "agitação de superfície, as ondas que as marés elevam em seu longo movimento"? (BRAUDEL, 1992, p. 14). Ele demonstra, num primeiro momento, o quanto a ação individual é que põe em movimento, de fato, a experiência histórica. Se não fosse o professor Freire ter agido da maneira como afirma o Inspetor Geral da Província, a escola sob sua responsabilidade não teria caído em descrédito, o inspetor paroquial da Lapa não teria tido que ir visitar aquela escola e, talvez, as próprias informações sobre a carreira docente - que ao que parece só foram dadas por Geniplo e ele - não precisariam ser prestadas às autoridades do ensino um mês antes do abandono da escola por parte do professor. Essa capacidade de ação pode ser notada, inclusive, se percebermos o impacto que o modo de proceder do professor parece ter causado na pequena vila onde exercia o magistério: os alunos começaram a abandonar a escola e os concidadãos o tinham em pior conta. Assim, a conduta do indivíduo, afetou os resultados de sua escola e, por meio dela, da própria imagem da escola da Província, a ponto do paradeiro dado à situação ter sido noticiado pelo Inspetor ao Presidente da Província, que, do seu lugar de discurso, anexando o relatório do Inspetor ao seu, prestava contas à Assembléia Provincial quanto ao modo pelo qual este dava conta de administrar o Paraná, e, dentre a ampla gama de atribuições impostas por este lugar de poder, a instrução pública.

Num segundo momento, nosso acontecimento demonstra que a ação individual é também ela um ato social, uma vez que se harmoniza ou não em relação a um conjunto maior de expectativas que pairam sobre o indivíduo ou sobre a categoria social na qual está inserido. Dessa forma, por trás do "não encaixe" do professor Freire a um padrão social 
desejado para os professores públicos naquele contexto, ele nos aponta uma série de atributos considerados desejáveis a essa categoria de sujeitos: a sobriedade, o bom comportamento moral, o respeito conquistado por esse conjunto de atitudes socialmente esperadas e, por último e não menos importante, o bom desempenho de sua função como professor, que incluía não abandonar a escola, sem a devida permissão dos superiores. Mas a ação de Francisco Bueno Freire revela algo mais: o quanto a identidade da escola, naquele período, ainda era dependente da identidade e conduta do próprio professor. Embora se reconhecesse que a escola era pública, mantida pelo governo da Província, a associação mais recorrente que parece que se fazia sobre a escola era aquela que a colocava em relação direta com a imagem do professor, sugerindo o quanto, para a afirmação da escola, o Estado dependeu da colaboração também dos seus funcionários. $\mathrm{O}$ fato da conduta pessoal do professor ser alvo da atenção na Vila do Rio Negro, por sua vez, é forte indício de que se a escola ainda não estava de todo assimilada, a função de professor público já era visível e talvez tenha sido nessa associação mais antiga que o Estado encontrou um dos caminhos para a aceitação da própria escola, a tal ponto que o desvio de conduta do mestre, que punha em risco a credibilidade da instituição escolar com o perdão do anacronismo - precisava ser investigado e sanado, para que ela não fracassasse na Vila do Rio Negro.

Não obstante esse lugar social como professor, colado à sua identidade, Francisco também parece ter sido um homem possuidor de sonhos, desejos, aspirações. Mas, nesse ponto, começamos de fato a adentrar naquele terreno movediço e arriscado do acontecimento, que Braudel, designava como sendo a parte do tempo tripartido

...mais apaixonante, a mais rica em humanidade, a mais perigosa também. Desconfiemos dessa história ainda ardente, tal como os contemporâneos a sentiram, descreveram, viveram, no ritmo de sua vida, breve como a nossa. Ela tem a dimensão de sua cólera, de seus sonhos e ilusões (BRAUDEL, 1992, p. 14).

Quais seriam os sonhos, os desejos, as ilusões do homem Francisco, que, talvez, não tenham se adaptado bem à profissão que ele exercera? Afinal, vale recordar que no ofício do Inspetor Paroquial da Lapa, já citado anteriormente, consta a informação de que Francisco deixara uma carta, onde afirmava não achar-se com a capacidade precisa para exercer o magistério. Se essa capacidade era a mesma que seus superiores julgavam nele ausente, não se pode precisar. Se fizermos uma comparação entre a trajetória do professor Geniplo e do professor Francisco, talvez, possamos encontrar um pouco do homem Francisco, debaixo da roupa do professor público. O professor Geniplo parece-nos ter sido um homem de "raízes", que tinha por hábito permanecer mais tempo no mesmo lugar e inclusive no lugar de exercício de sua profissão, segundo as informações que prestou em 1872. O professor Francisco, porém, parece-nos ser mais dado a uma certa mobilidade, tanto que entre 1864 e 1865, esteve em três lugares e em três escolas diferentes. Ainda que tendo se "assentado" em Rio Negro a partir de 1865, suas licenças bem mais longas que a do professor da Lapa - licenças sempre de dois meses, continuam a sugerir-nos esse seu gosto pelo "movimento". E ao abandonar sua cadeira e com ela sua profissão de professor público, toma novamente o caminho da estrada, indo, na expressão do presidente da Província, rumo à localidade de Campos Novos... Aqui, precisamos reconhecer a dificuldade de uma interpretação mais assertiva em torno desta característica de Francisco, que acompanhou-o durante parte de sua carreira docente, marcando também o fim dela. Seria esse seu desejo pelo movimento, pelo novo, pelas andanças, a causa última de sua conduta e das atitudes que o levaram - ou quiçá quis que o levassem - a novos rumos e à 
"campos novos"? Seria essa mobilidade por várias cidades e escolas um indício dessa dificuldade de adaptação à profissão escolhida e, desse modo, sua afirmação de que não se achava com capacidade para exercer o magistério, uma afirmação demoradamente meditada e medida e, só ao fim, anunciada? Não há nada, nenhuma evidência ou testemunho, que nos autorize a responder tais questões. O que podemos dizer é que esse universo de silêncios relativos a tais interrogações em torno da vida de Francisco podem ter informado sua experiência como professor e, por sua vez, ter se ligado também ao acontecimento do abandono de uma escola e toda a agitação que causou. Mas, ao revelar indícios da relação do professor com a sociedade do seu tempo, aponta o papel importante que esta categoria de sujeitos teve na afirmação da escola, não nos deixando esquecer que ela, assim como todos os fenômenos históricos, é feita de pessoas, tão humanas e inquietas como nós mesmos. E o arquivo, com toda sua força de memória, não consegue esconder isso daqueles que dele se achegam e se servem, com vistas à produção do conhecimento histórico.

\section{3. À modo de conclusão}

Ao término dessas reflexões que me reconduziram - e espero terem conseguido conduzir o leitor - ao Arquivo Público da Lapa e a experiência de nele realizar pesquisas em história da educação, gostaria de apresentar três ligeiras considerações que sintetizam os aspectos que considero relevantes, à modo de conclusão.

Em relação à riqueza de acervo dos arquivos locais, este situado na Lapa não me parece ser o único desse tipo, muito pelo contrário, um dentre muitos. Todavia, em função da relativa distância que se encontram dos grandes centros - ou dos programas de pósgraduação - ficam quase sempre esquecidos e, embora acessíveis aos historiadores, acabam sendo preteridos aos arquivos estaduais ou institucionais. Desejei, assim, ao pensar na minha trajetória de pesquisa no Arquivo da Lapa, divulgá-lo; mas, ao mesmo tempo, como outros historiadores já o fizeram em vários momentos, chamar a atenção para o investimento na localização e trabalho com os arquivos municipais, nos quais muitas memórias sobre a educação aguardam por serem interrogadas e convertidas em história(s) da educação.

Naquilo que diz respeito ao Arquivo como Lugar de Memória - Lugar para a História, ao término de uma pesquisa e das reflexões aqui empreendidas, considero que um não poderia existir sem o outro, mas também, que o último não pode se deixar vencer pelo primeiro. É a tarefa do historiador realizar este trabalho a partir do Arquivo, não para dizer que a história que escreve é melhor que a memória, mas para reafirmar constantemente que esta nada mais é que um dos inúmeros elementos que compõe e decompõe as experiências históricas e, sobretudo, as vidas dos homens e mulheres sobre os quais procuramos nos achegar, conhecer e compreender a cada vez que transpomos as portas de um Arquivo.

Por fim, ao apresentar o diálogo com os documentos do Arquivo a partir de três dimensões de análise, espero ter conseguido evidenciar que não se tratam de elementos distintos e presentes somente num ou noutro tipo de documento escrito. Antes, elas estão presentes em todo e qualquer testemunho histórico e, por essa razão, são dimensões, que cabe ao historiador operar, mover e deslocar, para cercar de várias formas e com vários olhares as evidências históricas que por meio deles se pode conhecer. Essas dimensões formuladas a partir do diálogo que busquei travar entre a teoria e a empiria refletem um modo pelo qual acredito ter conseguido ouvir algumas das vozes silenciosas que se pode escutar no Arquivo, lugar de memória e lugar para a História, numa última palavra, aquilo 
que a historiadora francesa Arlette Farge chamava de barulhos, "barulho por baixo da história" (FARGE, 1999, p. 93)

Fontes

APMCM. $3^{\circ}$ Livro Copiador da Câmara Municipal da Vila do Príncipe. Caixa 6, códice manuscrito.

manuscritos.

Balanços da Câmara Municipal da Lapa 1882-1889. Caixa 6, documentos

Ofício da Professora Rita Idalina de Carvalho ao Inspetor Paroquial da Lapa. Lapa, 20 de novembro de 1877,caixa 13, documento manuscrito.

Ofício do Inspetor Geral da Instrução Pública da Província do Paraná ao Inspetor Paroquial da Lapa. Curitiba, 16 de novembro de 1872, caixa 13, documento manuscrito.

Ofício do professor Francisco Bueno Freire ao Inspetor Geral da Instrução Pública. Rio Negro, 15 de outubro de 1872, caixa 13, documento manuscrito.

Ofício do professor Geniplo Pereira Ramos ao Inspetor Geral da Instrução Pública. Lapa, 12 de outubro de 1872, caixa 13, documento manuscrito.

Ofício do Sub-inspetor da Vila de Rio Negro ao Inspetor Paroquial da Lapa. Rio Negro, 27 de novembro de 1872, caixa 13, documento manuscrito.

Parecer da Câmara dos Vereadores da Lapa relativo ao ano de 1873. Caixa 6, documento manuscrito.

CARVALHO, C. A. Relatório apresentado à Assembléia Legislativa do Paraná por ocasião da Instalação da $1^{a}$ Sessão da $15^{a}$ Legislatura no dia $1^{\circ}$ de outubro de 1882 pelo presidente da Província o Exmo. Sr. Dr. Carlos Augusto de Carvalho. Curitiba: Typographia Perseverança, 1882.

LAMENHA LINS, A. Relatório apresentado à Assembléia Legislativa do Paraná no dia 15 de fevereiro de 1876 pelo Presidente da Província o Excelentíssimo Senhor Doutor Adolpho Lamenha Lins. Curiitba: Typographia da Viúva Lopes, 1876.

PARANÁ. Lei n. 734 de 22 de outubro de 1883. in: MIGUEL, M. E. B.; MARTIN, S. D. (orgs.) Coletânea da Documentação Educacional Paranaense no período de 1854 a 1889. Brasília: INEP, cd-room.

Portaria de 5 de outubro de 1854. in: MIGUEL, M. E. B.; MARTIN, S. D. (orgs.)

Coletânea da Documentação Educacional Paranaense no período de 1854 a 1889.

Brasília: INEP, $c d$-room. 
SOUZA, J. F. O. Relatório apresentado pelo Inspetor Geral João Franco de Oliveira Souza ao Presidente da Província Dr. Venâncio de Oliveira Lisboa. Curitiba: Typographia Paranaense, 1872.

VASCONCELOS, Z. G. Relatório do Presidente da Província do Paraná, o Conselheiro Zacarias Goes de Vasconcelos, na abertura da Assembléia Legislativa Provincial em 15 de Julho de 1854. Curitiba: Typographia Paranaense de Cândido Martins Lopes, 1854.

\section{Referências}

BLOCH, M. L. B. A Apologia da História ou o Ofício do Historiador. Rio de Janeiro: Zahar, 2001.

BRAUDEL, F. O Mediterrâneo e o mundo mediterrâneo à época de Filipe II. Extraído do Prefácio. In: Escritos Sobre a História. São Paulo: Perspectiva, 2007, p. 13-16.

BURKE, P. O mundo como teatro - estudos de antropologia histórica. Lisboa: Difel, 1992.

CARVALHO, M. M. C.; NUNES, C. Historiografia da Educação e fontes. In: GONDRA, J. G. (org.) Pesquisa em História da Educação no Brasil. Rio de Janeiro: DP\&A, 2005, p. 17-62.

ELIAS, N. A sociedade da Corte. Rio de Janeiro: Zahar, 2001.

A sociedade dos indivíduos. Rio de Janeiro: Zahar, 2009.

FARGE, A. Lugares para a História. Lisboa: Teorema, 1999.

O Sabor do Arquivo. São Paulo: EDUSP, 2009.

KUBO, E. M. A Legislação e a Instrução Pública de Primeiras Letras na $5^{\text {a }}$ Comarca da Província de São Paulo. Curitiba: SECE, 1986.

NORA, P. Entre memória e história: a problemática dos lugares. Revista do Projeto História. São Paulo, n. 10, dezembro 1993, p. 7-28.

NUNES, C. História da educação: espaço do desejo. Em Aberto. Brasília, n. 47, julhosetembro 1990, p. 37-46.

RAGAZZINI, D. Para quem e o que testemunham as fontes da História da Educação? Educar em Revista. Curitiba, n. 18, 2001, p. 13-28.

REVEL, J. Retornar ao acontecimento - um itinerário historiográfico. In: Proposições: ensaios de história e historiografia. Rio de Janeiro: Eduerj, 2009, p. 73-96. 
THOMPSON, E. P. A miséria da teoria ou um planetário de erros. Curitiba: Copyflet, 2009.

VEYNE, P. Como se escreve a história. Brasília: Editora UNB, 1998.

\begin{abstract}
${ }^{1}$ O presente artigo, fruto da experiência de pesquisa de mestrado, contou com apoio financeiro da CAPES-REUNI.

${ }^{2}$ Doutorando em Educação, na Linha de História e Historiografia da Educação, Universidade Federal do Paraná, juarezdosanjos@yahoo.com.br.

${ }^{3}$ Aqui é importante uma ressalva em relação à documentação da Câmara Municipal da Lapa. Uma parte significativa do seu acervo encontra-se atualmente sob a custódia do Arquivo Público do Paraná, recebida como doação da família da historiadora Cecília Maria Westphalem, num fundo que leva o seu nome. Para fins deste artigo, limito-me a explorar apenas a documentação localizada na Lapa, o que, de certo modo, não permitirá indicar a partir de documentos ali existentes os diversos momentos nos quais a Câmara pronunciouse sobre a instrução pública na Lapa. Todavia, assinalo que, na documentação arquivada em Curitiba - mas que diz respeito à ação da Câmara da Lapa sobre a instrução -, constam atestados emitidos para professores públicos, reivindicações para a reabertura de escolas, opiniões sobre a organização das escolas e críticas à abolição do toque do sino para o anúncio do início das aulas na Vila, todas situações nas quais, de um ou outro modo, as autoridades municipais se posicionam, para apoiar (com menos freqüência) e sobretudo, questionar o modo com a Província intervinha na escola.

4 Ainda hoje, mesmo após inúmeros desmembramentos, a Lapa permanece como o quarto maior município em extensão territorial no Paraná.
\end{abstract}

Recebido em: outubro-11

Aprovado em: fevereiro-12 